\title{
O DESJEJUM DOS ALUNOS DAS QUATRO PRIMEIRAS SÉRIES DE NİVEL I DAS ESCOLAS DA REDE MUNICIPAL DE ENSINO DE SÃO PAULO, SP - BRASIL *
}

Rosenburg, O. O desjejum dos alunos das quatro primeiras séries de nivel I das escolas da Rede Municipal de Ensino de São Paulo, SP - Brasil. Rev. Saúde públ., S. Panlo, $11: 465-79,1977$.

REsumo: Foi estudada uma populaçäo de 380 alunos das quatro primeiras séries de nivel I, das Escolas da Rede Municipal de Ensino de Sáo Paulo (Brasil) com a finalidade de conhecer a composifão do desjejum desses esco. lares. Os resultados mostraram: a) um contingente de $12.63 \%$ das criancas vai $\dot{a}$ escola em completo jejum; b) a média do consumo de calorias no desjejum foi igual a $10,57 \%$ das necessidades diárias, de acordo com a idade e o sexo, e o consumo mais freqüente foi de 5 a menos do que $10 \%$ dessas necessidades; c) a média do consumo de proteinas foi igual a $17,29 \%$ das necessidades diárias. $e$ o consumo mais freqüente foi de zero a menos do que $5 \%$ dessas necessidades; d) a média do consumo de lipides foi igual a 6,7 gramas, e o consumo mais freqüente foi de zero a menos do que 5 gramas; e) a composicáo centesimal do desjejum caracterizoutse por uma participaçáo excessiva do componente glicidio, em detrimento do protidico e, principalmente, do lipidico.

Unitermos: Criança, nutrição. Inquéritos nutricionais, Säo Paulo, Brasil. Desnutrição.

\section{IN TRODUÇ $\mathrm{A} O$}

E fato reconhecido yue, na cidade de São Paulo, dentro do quadro alimentar diário, o desjejum contribui apenas com a menor parcela (Pierson ${ }^{15}, 1942$ ). Segundo outras pesquisas (Harris ${ }^{10}, 1970$ ), essa modicidade se apresenta como um fenômeno universal.

Aceito o caráter limitado da primeira refeição, impõe-se a necessidade de pesquisar a natureza e o grau da limitação, principalmente na faixa etária que mais the sofre as consequiencias, ou seja, a da criança que vai à escola pela manhà.

As pesquisas sobre o desjejum do escolar, entre nós, tiveram início no ano de 1942, com os trabalhos de Dante Costa. A eles seguiram-se, em São Paulo, mençōes sobre a matéria, por Giulianelli " (1961) e o estudo de Meira ${ }^{14}$ (1963) con universitários.

Parte da tese de doutoramento apresentada à Faculdade de Saúde Pública da USP. em 1976.

* Do Departamento de Saúde Materno-Infantil da Faculdade de Saúde Pública da USP - Av.

Dr. Arnaldo, 715 - São Paulo. SP - Brasil. 
TiOSENBURG, O. O desjejum dos alunos das quatro prineiras séries de nível I das escolas da Rede Municipal de Ensino de São Paulo, SP - Brasil. Rer. Stúde públ., S. Paulo, 11: $465-79,1977$.

A necessidacle de obter dados mais recentes e completos parecia urgente.

No ano de 1972, o Programa de Alimentação do Departamento de Assistência Escolar da Municipalidade, ressentia-se da falta de conhecimentos sobre o desjejum dos alunos da Rede Escolar Municipal, e de certas informaçōes que permitiriam melhor adequar o Programa Merenda, desse Departamento, às necessidades das crianças por ele beneficiadas. Foi então planejado um inquérito no qual se recolheram dados que, entre outros, forneceram matéria para esta pesquisa.

Desnecessário é acentuar o caráter limitado das inferências a que o exame de apenas a menor fração do dia alimentar permite chegar. Entretanto, é oportuno lembrar que, se a um desjejum pobre não correspondem necessariamente refeições outras também pobres, a escassez no almoço e no jantar é sempre caudatária de um desjejum igualmente escasso. Ou de nenhum desjejum.

\section{POPULAÇÁ E METOdOS}

A população objeto do estudo é constituida por crianças das quatro primeiras séries do nivel l, matriculadas no periodo da manhã, da Rede Municipal de Ensino de São Paulo. Esta rede distribui as suas escolas de acordo com a divisão administrativa da Prefeitura, isto é, pelas chamadas Administrações Regionais (AR), em número de 16. Estas foram, neste estudo, redistribuidas em três zonas: Central (3 Regionais), Intermediária (6 Regionais) e Periférica ( 7 Regionais), adotando-se os critérios de Leser e Barbosa 12, usados na caracterização dos Distritos Sanitários do municipio de São Paulo. O estudo definitivo, realizado no ano de 1974 , foi precedido por um estudo-piloto, efetuado em 1973.

\subsection{Estudo-Piloto}

A população deste estudo foi constituida por 102.914 alunos matriculados no periodo da manlaá, nas quatro primeiras séries de nivel l, de 240 escolas municipais.

Para a seleção da amostra-piloto, constituida por 200 escolares, empregou-se um sistema de amostragem por etapa dupla. $\mathrm{Na}$ primeira etapa foi aplicada amostragem casual simples de 25 escolas, e, na segunda, em cada escola foram selecionadas 8 crianças, sendo duas de cada série.

Diante da circunstância do não funcionamento de algumas séries no periodo da manhã, o numero de escolares sorteados, de 200, reduziu-se a 160 .

De cada aluno participante do estudopiloto, foram obtidas as seguintes informações:

1) as constantes de um formulário de 13 perguntas (12 das quais ligadas ao Programa Merenda), sendo a diretamente relacionada com o objetivo do presente estudo a seguinte: "9. O que comeu (o aluno) antes de vir à escola?” Tal formulário foi preenchido duas vezes para cada criança, sendo uma com respostas obtidas do aluno, na escola; e outra, com as obtidas da mãe ou responsável, no mesmo dia, em inquérito domiciliar;

2) o peso e o volume dos alimentos consumidos pelo escolar na primeira refeição do mesmo dia, através de inquérito domiciliar, e segundo informações obtidas das mães ou responsáveis (método recordatório, associado ao de pesagem direta dos alimentos);

3) o cardápio da merenda oferecida na escola, no dia do inquérito, com o valor calórico total, e a quantidade, em gramas, dos prótides, glicides e lípides.

O estudo-piloto teve como objetivos principais: 
ROSENBURG, O. O desjejum dos alunos das quatro primeiras séries de nível I das escolas da Rede Municipal de Ensino de São Paulo, SP - Brasil. Rev. Saúde puibl., S. Paulo, 11: $465-79,1977$.

$\left.1^{\circ}\right)$ Fazer o treinamento do pessoal.

$2^{\prime \prime)}$ Testar a viabilidade do trabalho de cainpo segundo duas alternativas:

a) en nivel exclusivamente escolar, con dados obtidos do atuno;

b) em nivel escolar e domiciliar, con informações recebidas do aluno, na escola, e da mãe ou lesponsável, na residência.

3") Fornecer dados para a amostragem do estudo definitivo.

4.) Possibilitar a análise das intercorrências das diferentes fases do trabalno de campo.

Dentre 160 crianças efetivamente sorteadas, houve uma perda de 27 inquéritos $(16,87 \%)$, pelos motivos seguintes:

$$
\begin{aligned}
& \text { ne } \% \\
& \text { - Responsáveis não encontrados . } 23=14,37 \\
& \text { - Responsável embriagado ....... } 1=6,62 \\
& \text { - Responsável não fala português } 1=0,62 \\
& \text { - Responsável não sabe informar } 1=0,62 \\
& \text { - Residência não encontrada ... } 1=0,62 \\
& \text { Total } \\
& \text { - }
\end{aligned}
$$

No inquérito domiciliar, após o interrogatório da criança na escola, as visitadoras tizeram-se por ela acompanhar.

No confronto das respostas ao item 9 do formulário, relativo aos alimentos constituintes do desjejum, e obtidas paralelamente do escolar, e da mãe ou responsável, o resultado foi, para 130 formulários estudados:

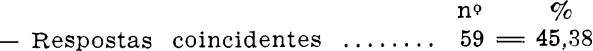

$$
\begin{aligned}
& \text { - Respostas não coincidentes .. } 71=54,61
\end{aligned}
$$

\subsection{Estudo Definitivo}

\subsubsection{População}

Constituída por 104.638 alunos matriculados no período da manhã nas quatro primeiras séries de nível I, de 246 escolas municipais, no ano de 1974.

\subsubsection{Tamanho da Amostra}

Com dados obtidos no estudo-piloto, a amostra calculada foi de 390 escolares. Tendo em vista a compensação das perdas, o tamanho da amostra foi aumentado para 456 crianças.

\subsubsection{Processo de Amostragem}

Foi adotado um processo de amostragem equiprobabilística por duas etapas:

- 1. Etapa: foram selecionadas 76 escolas, entre 246 , com probabilidade proporcional ao tamanho. A distribuição das escolas foi a seguinte:

Zona Periférica: 42 escolas sorteadas

Zona Intermediária: 31 escolas sorteadas

\section{Zona Central: 3 escolas sorteadas}

- $2^{a}$ Etapa: em cada escola selecionada foram sorteados 6 alunos pelo processo de amostragem sistemática.

\subsubsection{Inquérito e Informações}

Tendo em vista os resultados do estudopiloto, o inquérito foi conduzido no sentido de serem obtidas as seguintes informações:

a) As constantes de um formulário de 14 perguntas (13 das quais de interesse do citado Programa Merenda), no qual, parte das respostas (8) seriam obtidas na Escola, da criança, e parte (6) da mãe ou informante fidedigno, na residência do aluno, no mesmo dia.

b) $\mathrm{O}$ peso e o volume dos alimentos consumidos pela criança na primeira refeição do dia escolhido, através de inquérito domiciliar e segundo informações obtidas das mães ou responsáveis (método recordatório associado ao de pesagem direta dos alimentos).

c) O cardápio da merenda oferecida à criança na escola, no dia do inquérito, com 
ROSENBtRG, O. O desjejum dos alunos das quatro primeiras series de nivel I das escolas da Rede Municipal de Ensino de São Paulo. SP - Brasil. Rer. Saúde públ, S. Paulo, 11 465-79, 1977.

o respectivo valor calórico total e a cuantidade, em gramas, dos glicides, lipides e prótides.

O trabalho de campo realizou-se nos dias 16 a 20 e 23 a 26 de setembro de 1974 , pela manhã, com 28 visitadoras trabalhando en duplas. No caso de criança ausente, ou de residencia fechada, foram teitos 1 ou 2 repasses.

A análise dos nutrientes do cesjejum foi feita usando-se tabelas de composição de alimentos: $: 5.13,17$.

Para pesagem e medida volumétrica dus alimentos foram utilizadas Balanças Marti $(10 / 10 \mathrm{~g})$ e canecas de $500 \mathrm{ml}(10 \cdot 10 \mathrm{ml})$.

O cálculo clas necessidades em calorias e proteinas, segundo idade e sexo, foi feito segundo as "Recomendaçóes Nutricionais Diárias/Inan - Outubro de 1974"

\section{RESULTADOS}

\subsection{Inquéritos nāo realizados}

Dentre as 456 crianças sorteadas, houve $u m$ total de 76 inquéritos perdidos, equivalente a $16,66 \%$ dos alunos sorteados. As principais causas das perdas foram: alunos eliminados (30), alunos ausentes (11) e falta de informantes (10).

\subsection{Cobertura calórica e protidica do desjejum em relação às necessidades diárias}

Calculada a cobertura correspondente às calorias e as proteinas consumidas no desjejum, em termos de necessidades diárias segundo a idade e o sexo, e em percentual, us resultados obtidos, em relação à média para as crianças do estudo e os três grupos de regionais encontram-se nas Tabelas 1 e 3.

TA B E L A 1

Desjojum - Valor médio da cobertura calórica (\%) em relação às necessidades diárias Crianças do Estudo e Zonas Urbanas.

\begin{tabular}{|c|c|c|c|}
\hline Populacão & Média $(\%)$ & Desvio-Padrão & $\begin{array}{l}\text { No de } \\
\text { Crianças }\end{array}$ \\
\hline Crianças do Estudo & 10.6 & 7.5 & 380 \\
\hline Zona Periferica & 9,7 & 7.3 & 201 \\
\hline Zona Intermediária & 11.7 & 7,8 & 162 \\
\hline Zona Central & 9.6 & 5,1 & 17 \\
\hline
\end{tabular}

A distribuição das crianças, segundo essa cobertura, pode ser verificada nas Tabelas 2 e 4.

\subsection{Valores absolutos do consumo de $c a-$ lorias $e$ de nutrientes no desjejum}

Os cálculos relativos ans valores absolutos do consumo de calorias, prótides, gli- cides e lipides, na primeira refeição, deram os resultados constantes da Tabela 5 .

Feita a distribuição segundo o consumo de calorias, os resultados encontram-se na Tabela 6.

A distribuição das crianças do estudo segundo o consumo de proteínas, glicides e lipides, encontra-se nas Tabelas 7,8 e 9 . 
ROSENBURG, O. O desjejum dos alunos das quatro primeiras séries de nírel I das escolas da Rede Municipal de Ensino de São Paulo, SP - Brasil. Rer. Saúde públ., S. Paulo, 11: $465-79,1977$.

\section{T A B E L A 2}

Desjejum - Distribuição do numero, percentagen e percentagem acumulada das Crianças do Estudo segundo a cobertura calórica (\%) em relação às necessidades dıárias.

\begin{tabular}{|c|c|c|c|c|}
\hline \multicolumn{2}{|c|}{$\begin{array}{c}\text { Cobcrturat Caloricis } \\
(\% / /)\end{array}$} & \multicolumn{2}{|c|}{ Crianças } & $\begin{array}{l}\text { Percentagen } \\
\text { Acumuladit }\end{array}$ \\
\hline 0 & -5 & 91 & 23.9 & 23.9 \\
\hline 5 & -10 & 100 & 26.9 & 50.2 \\
\hline 10 & $-\quad 15$ & $9 \div$ & 24.5 & 74.7 \\
\hline & -2 & 55 & 14,5 & 89.2 \\
\hline 20 & -25 & 26 & 6.8 & 96.1 \\
\hline 25 & -80 & 7 & 1.8 & $9 \pi .9$ \\
\hline 30 & -35 & 7 & 1.8 & 99.7 \\
\hline & $+\quad 40$ & $\ldots$ & - & 93.7 \\
\hline 40 & :- 45 & 1 & $0 . \therefore$ & 100.0 \\
\hline Total & & 380 & 100.0 & 100.0 \\
\hline
\end{tabular}

TA B E I A

Desjejun - Valor médio da cobertura protidica (\%) em relaçào às necessidades diárias Crianças do Estudo e Zonas Urbanas.

\begin{tabular}{|c|c|c|c|}
\hline Populaçào & Média $1 \%$ & Desvio-Padrāo & $\begin{array}{c}\text { No de } \\
\text { Crianças }\end{array}$ \\
\hline Zona Perifélica & $16: 1$ & 13.6 & 201 \\
\hline Zona Intemediál’i & 19.0 & 14.11 & 162 \\
\hline Zona Central & 15.4 & 9.0 & 17 \\
\hline
\end{tabular}

T A B E L A 4

Desjejum - Distmbução do múmero, percentagen e percentagen acumulada das Criancas do Estudo segundo a cobertura protidica $(\%)$ em relação às necessidades diârias.

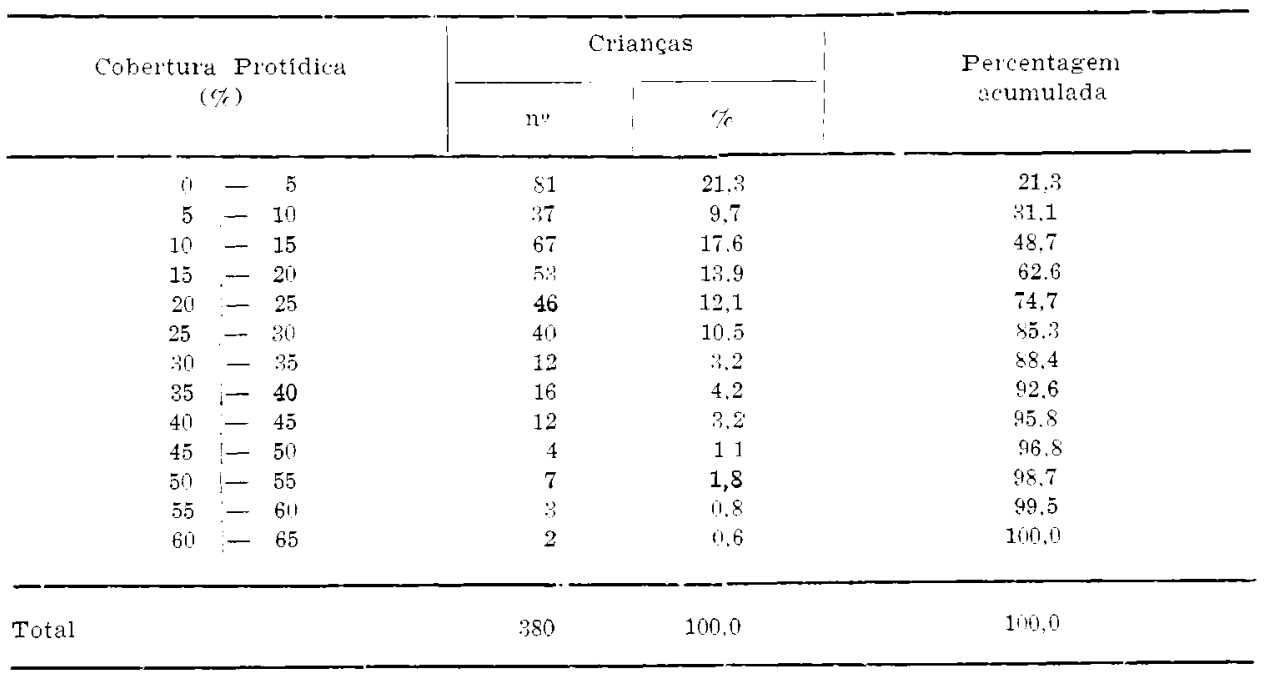


ROSENBURG, O. O desjejum dos alunos das quatro primeiras séries de nível I das escolas da Rede Municipal de Ensino de São Paulo, SP - Brasil. Rev. Saúde públ., S. Paulo, 11: $465-79,1977$.

TA B E L A 5

Desjejum - Valores mínimos, máximos, médios, desvios-padrão ( $\mathbf{s}$ ), coeficiente de variação de Pearson (\%) e amplitude de variação das calorias e dos nutrientes (em gramas) Crianças do Estudo.

\begin{tabular}{|c|c|c|c|c|c|c|}
\hline Consenso & $m$ & $s$ & $\begin{array}{c}\text { Amplitude } \\
\text { de variação }\end{array}$ & min. & $\max$ & $\begin{array}{c}\text { Coef. de } \\
\text { variação de } \\
\text { Pearson (\%) }\end{array}$ \\
\hline Calorias & 246,3 & 175,8 & 914,9 & 0,00 & 915,0 & 71,4 \\
\hline Proteínas & 6,8 & 5,3 & 27,1 & 0,00 & 27,1 & 78,8 \\
\hline Glicides & 39,7 & 28,2 & 180,2 & 0,00 & 180,2 & 71,1 \\
\hline Lipides & 6,7 & 6,9 & 41,4 & 0,00 & 41,4 & 102,5 \\
\hline
\end{tabular}

T A B E L A 6

Desjejum - Distribuição do número, percentagem e percentagem acumulada das Crianças co Estudo scgundo o consumo de calorias.

\begin{tabular}{|c|c|c|c|c|c|}
\hline & \multirow{2}{*}{\multicolumn{2}{|c|}{ Calorias }} & \multicolumn{2}{|c|}{ Crianças } & \multirow{2}{*}{$\begin{array}{c}\text { Percentagem } \\
\text { acumulada }\end{array}$} \\
\hline & & & $n \%$ & $\%$ & \\
\hline & 0 & 100 & 82 & 21,6 & 21,6 \\
\hline & 100 & 200 & 73 & 19,2 & 40,8 \\
\hline & 200 & 300 & 102 & 26,8 & 67,6 \\
\hline & 300 & $1-400$ & 55 & 14,5 & 82,1 \\
\hline & 400 & 500 & 37 & 9.7 & 91,8 \\
\hline & 500 & 600 & 17 & 4,5 & 96,3 \\
\hline & 600 & 700 & 9 & 2,4 & 98,7 \\
\hline & 700 & 800 & 2 & 0,5 & 99,2 \\
\hline & 800 & 900 & 2 & 0,5 & 99,7 \\
\hline & 900 & $1-1000$ & 1 & 0,3 & 100,0 \\
\hline Total & & & 380 & 100,0 & 100,0 \\
\hline
\end{tabular}

T A B ELA 7

Dosjzjum - Distribuição do número, percentagem e percentagcm acumulada das Crianças do Estudo segundio o consumo de proteinas (em gramas).

\begin{tabular}{|c|c|c|c|c|}
\hline & \multirow{2}{*}{ Proteínas (g) } & \multicolumn{2}{|c|}{ Crianças } & \multirow{2}{*}{$\begin{array}{l}\text { Percentagem } \\
\text { acumulada }\end{array}$} \\
\hline & & n" & $\%$ & \\
\hline & $01-5$ & 149 & 39,2 & 39,2 \\
\hline & $51-10$ & 144 & 37,9 & 77,1 \\
\hline & $10[-15$ & 51 & 13,4 & 90,5 \\
\hline & $15-20$ & 29 & 7,6 & 98,2 \\
\hline & $201-30$ & 7 & 1.8 & 100,0 \\
\hline Total & & 380 & 100,0 & 100,0 \\
\hline
\end{tabular}


ROSENBURG, O. O desjejum dos alunos das quatro primeiras séries de nível I das escolas da Rede Municipal de Ensino de São Paulo, SP - Brasil. Rev. Saúde públ., S. Paulo, 11: $465-79,1977$.

T A B ELA 8

Desjejum - Distríbuição do número, percentagem e percentagem acumulada das Crianças do Estudo segundo o consumo de glícides (em gramas).

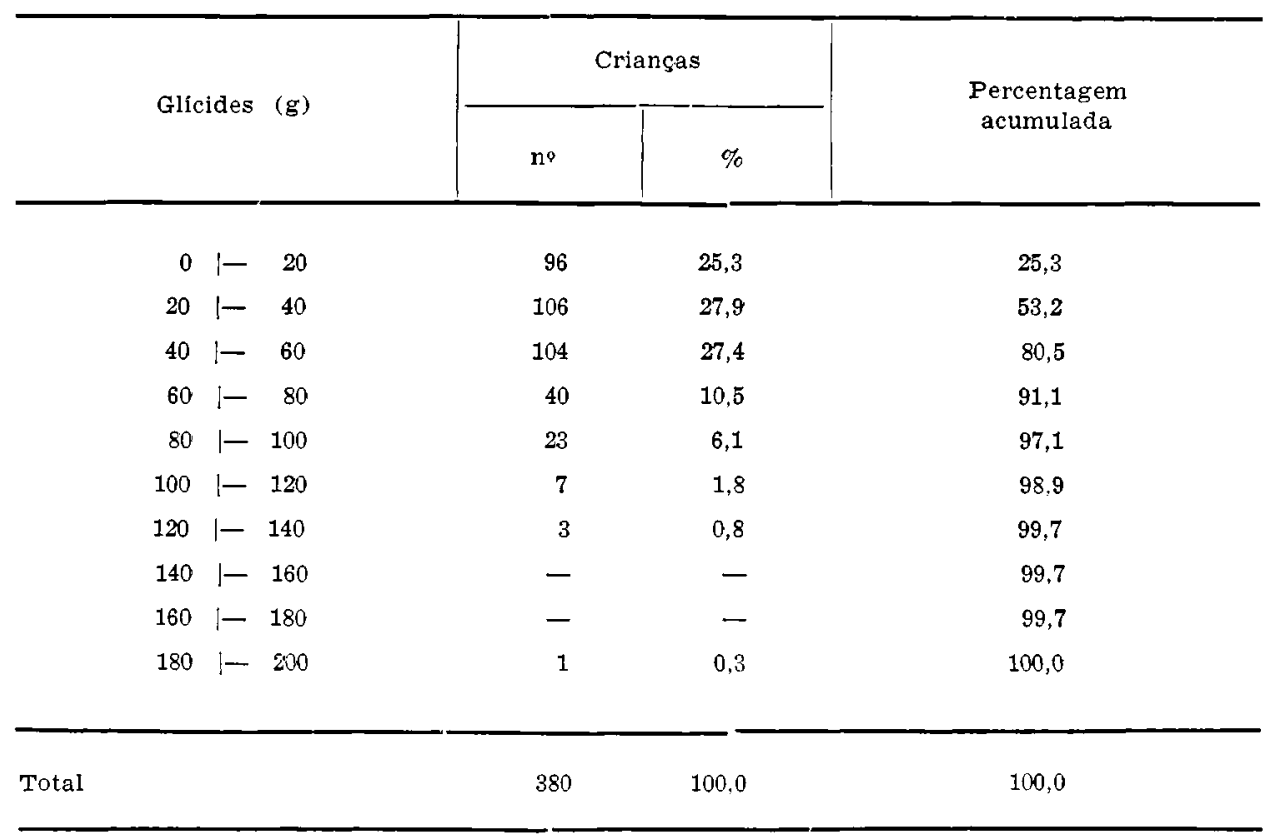

TABELA 9

Desjajum - Distribuição do número, percentagem e percentagem acumulada das Crianças do Estudo segundo o consumo de lipides (em gramas).

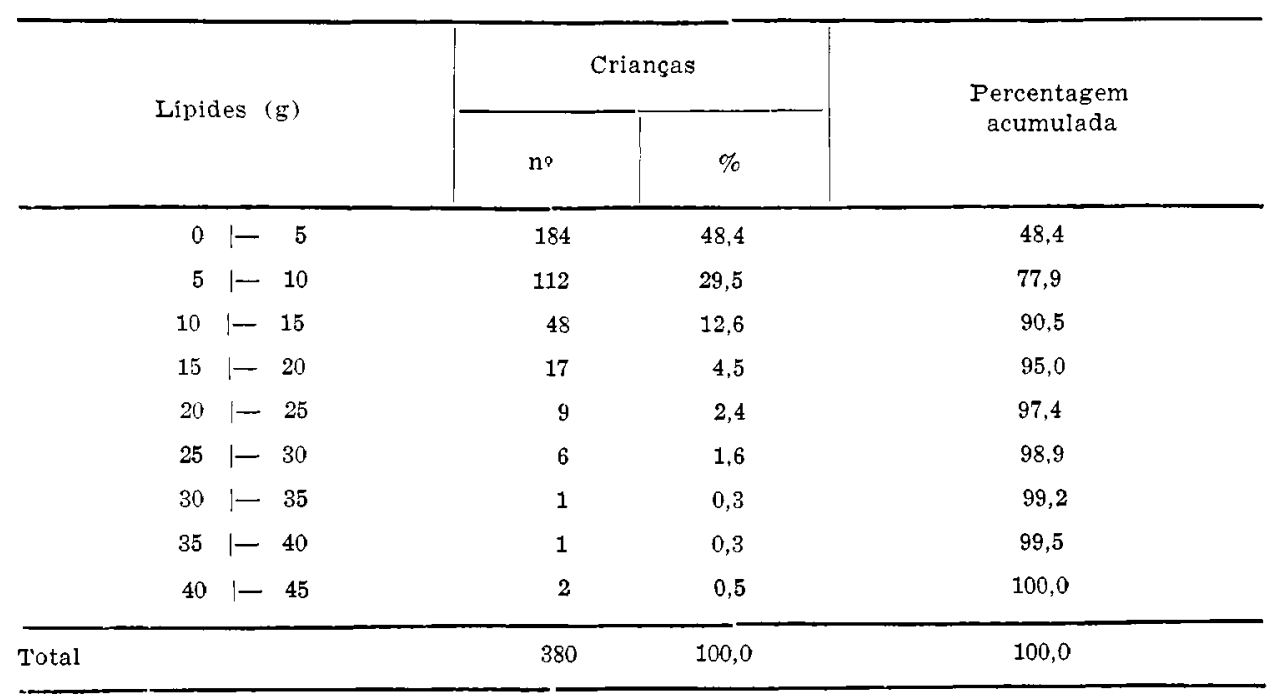


ROSENBURG, O. O desjejum dos alunos das quatro primeiras séries de nivel I das escolas da Rede Municipal de Ensino de Săo Paulo, SP - Brasil. Rev. Saúde públ, S. Paulo, 11: 465-79, 1977.

\subsection{Composição centesimal do desjejum}

Foi calculada segundo o mesmo esquema analítico até agora apresentado, cujos resultados encontram-se na Tahela 10.

A distribuição correspondente aus conlponentes glicídico, protídico e lipídico, fezse segundo as Tabelas $11,12,13$.

TA B E L A 10

Desjejum - Composição Centesimal - Valores médios $(\mathrm{m})$. mínimos, máximos, desvics-padrão (s), amplitude de variação e coeficiente de variação de Pearson (\%) - Crianças do Estudo.

\begin{tabular}{|c|c|c|c|c|c|c|}
\hline $\begin{array}{c}\text { Percentagem } \\
\text { calórjca }\end{array}$ & $\mathrm{m}$ & $s$ & $\begin{array}{l}\text { Amplitude } \\
\text { de variação }\end{array}$ & $\min$. & $\max$ & $\begin{array}{c}\text { Coef. de } \\
\text { variação de } \\
\text { Pearson }(\%)\end{array}$ \\
\hline Glicides & 58.1 & 26.5 & $10(1,0$ & 0,00 & 100,0 & 45.5 \\
\hline Prótides & 0.3 & 5,4 & 23.2 & 0,00 & $2 n, 2$ & 58,1 \\
\hline Lipides & 19.9 & 14.5 & 66.8 & 0.00 & 60.8 & $7: 3,2$ \\
\hline
\end{tabular}

T A B E L A 11

Desjejum - Composição centesimal - Distribuição do nümero, percentagem e percentagem acumulada das Crianças do Estudo segundo o compononte glicídico.

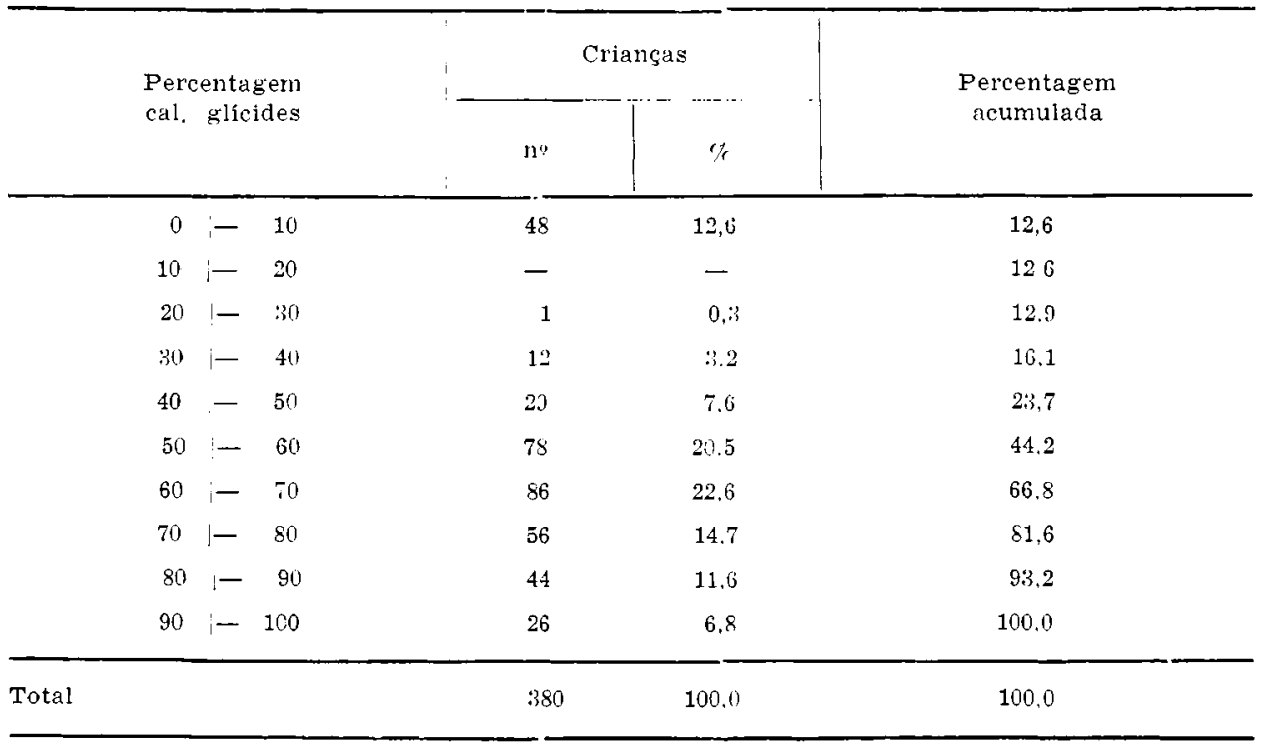


ROSENBURG, O. O desjejum dos alunos das quatro primeiras séries de nível I das escolas da Rede Municipal de Ensino de São Paulo, SP - Brasil. Rev. Saúde públ., S. Paulo, 11: 465-79, 1977.

\section{T A B E L A 12}

Desjejum - Composição Centesimal - Distribuição do número, percentagem e percentagem acumulada das Crianças do Estudo segundo o componente protídico.

\begin{tabular}{|c|c|c|c|c|}
\hline \multirow{2}{*}{\multicolumn{2}{|c|}{$\begin{array}{l}\text { Percentagem } \\
\text { cal. proteínas }\end{array}$}} & \multicolumn{2}{|c|}{ Crianças } & \multirow{2}{*}{$\begin{array}{l}\text { Percentagem } \\
\text { acumulada }\end{array}$} \\
\hline & & $n^{4}$ & $\%$ & \\
\hline & $0:-5$ & 80 & 21,1 & 21,1 \\
\hline & $5 \mid-10$ & 96 & 25.3 & 46,4 \\
\hline & $10-15$ & 160 & 42,1 & 88,5 \\
\hline & $15-20$ & 37 & 9,7 & 98,2 \\
\hline & $20-25$ & 7 & 1,8 & 100,0 \\
\hline Total & & 380 & 100,0 & 100,0 \\
\hline
\end{tabular}

T A B E L A 13

Desjejum - Composição Centesimal - Distribuição do número, percentagem e percentagem acumulada das Crianças do Estudo segundo o componente lipídico.

\begin{tabular}{|c|c|c|c|c|}
\hline \multirow{2}{*}{\multicolumn{2}{|c|}{$\begin{array}{l}\text { Percentagem } \\
\text { cal. lipides }\end{array}$}} & \multicolumn{2}{|c|}{ Crianças } & \multirow{2}{*}{$\begin{array}{l}\text { Percentagem } \\
\text { acumulada }\end{array}$} \\
\hline & & & & \\
\hline & $1-5$ & 101 & 26,6 & 26,6 \\
\hline & $1-10$ & 13 & 3,4 & 30,0 \\
\hline 10 & $1-15$ & 31 & 8,1 & 38,1 \\
\hline 15 & $1-20$ & 39 & 10,3 & 48,4 \\
\hline 20 & $1-25$ & 42 & 11,1 & 59,5 \\
\hline 25 & $1-30$ & 48 & 12,6 & 72,1 \\
\hline 30 & $1-35$ & 47 & 12,4 & 84,5 \\
\hline 35 & $1-40$ & 33 & 8,7 & 93,2 \\
\hline 40 & $j-45$ & 19 & 5,0 & 98,2 \\
\hline 45 & $1-50$ & 2 & 0,5 & 98,7 \\
\hline 50 & $1-55$ & - & - & 98,7 \\
\hline & $1-60$ & 3 & 0,7 & 99,4 \\
\hline 60 & $1-65$ & 1 & 0,3 & 99,7 \\
\hline 65 & $i-70$ & 1 & 0,3 & 100,0 \\
\hline & & 380 & 100,0 & 100,0 \\
\hline
\end{tabular}


ROSENBURG, $O$. O desjejum dos alunos das q uatro primeiras séries de nivel I das escolas da Rede Municipal de Ensino de São Paulo, SP - Brasil. Rev. Saúde públ., S. Paulo, 11: $465-79,1977$.

\subsection{Alunos que compareceram d̀s aulas em completo jejum}

O número total de crianças que nada receberam como desjejum foi igual a 48 , ou seja, a $12,63 \%$ das crianças pertencentes à amostra constituída por 380 escolares.

Considerando que as amostras das Zonas Periférica, Intermediária e Central são constituídas por 201, 162 e 17 escolares, respectivamente, o número e o percentual de crianças que Nada comeram, para cada uma dessas zonas, foi:

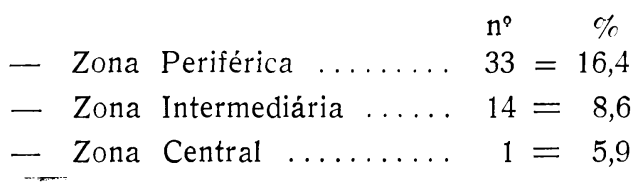

3.6. Composiçẫo do cardápio do desjejum

1) Consumo exclusivo de café (ou chá), com açúcar: 22 casos ou 5,78\% das Crianças do Estudo.

2) Consumo exclusivo de café (ou chá), com açúcar e pão: 31 casos ou $8,15 \%$ das Crianças do Estudo.

3) Número de casos em que o leite foi mencionado: 191 ou $50,26 \%$ das Crianças do Estudo.

4) Número de casos em que a margarina ou a manteiga foram mencioradas: 163 ou $42,89 \%$ das Crianças do Estudo.

5) Número de casos em que as frutas foram mencionadas: 6 ou $1,57 \%$ das Crianças do Estudo.

\subsection{Extensão dos alimentos usados no desjejum}

Alimentos $\quad \mathrm{N}^{\circ}$ de $\%$

Açúcar 30179,2

Pão (comum, doce) $\ldots \ldots \ldots .244 \quad 64,2$

Café $\quad \ldots \ldots \ldots \ldots \ldots \ldots \ldots, \quad 233 \quad 61,3$

Leite (fresco, em pó, condensado) $191 \quad 50,3$

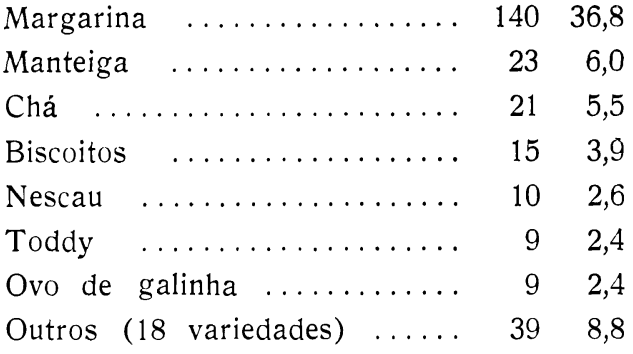

\section{DISCUSSAO}

A diversidade dos métodos adotados nos inquéritos alimentares relativos à criança em idade escolar levaram-nos a testar, em estudo-piloto, a viabilidade da obtenção de dados baseados exclusivamente no interrogatório direto do aluno, na escola, uma vez que, se aprovado, esse método simplificaria bastante o trabalho de campo. Mas, à vista do baixo coeficiente de respostas concordantes, quanto à natureza dos alimentos oferecidos à criança no desjejum, no formulário proposto concomitantemente à mãe e à criança, foram preferidas as informações maternas, dado o fato de que, na visita domiciliar, pôde ser comprovada a existência dos alimentos mencionados. A visita domiciliar acrescentaria, também, à informação verbal, os dados obtidos na pesagem direta dos alimentos.

\subsection{Coberturas calórica e protidica do desjejum}

$\mathrm{Na}$ alimentação da criança em idade escolar, a ração diária é distribuída em três ou quatro refeições. Dentre essas refeições, o desjejum, segundo Fonseca 7, "cobre 20 a $30 \%$ do total calórico diário".

Os autores anglo-saxões e americanos esperam, como Harris ${ }^{10}$, que o desjejum corresponda, no mínimo, a $25 \%$ das necessidades diárias em calorias e nutrientes essenciais. Mas o fato de que $96,1 \%$ das crianças do estudo não tenham alcançado uma cobertura de $1 / 4$ das suas necessidades calóricas na primeira refeição, é indi- 
ROSENBURG, O. O desjejum dos alunos das quatro primeiras séries de nível I das escolas da Rede Municipal de Ensino de São Paulo, SP - Brasil. Rev. Saúde públ., S. Paulo, 11: $465-79,1977$.

cativo de que o limite inferior em questão é, na população estudada, um limite utópico, atingido apenas por $3,9 \%$ dos alunos estudados (Tabela 2). Nesse contexto, parece mais razoável fixar o limite inferior sugerido por Fonseca $7-20 \%$ - como o minimo aceitável.

A recomendação quanto ao mínimo justitica-se por inúmeros motivos. Um deles é o de que certa parte da população submete-se a um regime de apenas três refeições diárias. Diante disso, o fato de que $89,2 \%$ das crianças do estudo recebam, no desjejum, uma taxa calórica inferior a $20 \%$ das suas necessidades diárias (Tabela 2) leva a concluir que o almoço e o jantar vão ser onerados com carga superior a $80 \%$, o que torna o problema de difícil solução.

Quanto às conseqüências imediatas, é oportuno mencionar a pesquisa de investigadores suecos (Arvedson e col., 1969), os quais observaram estudantes de 7 a 18 anos de idade. Nesse trabalho, não se constataram diferenças no rendimento escolar, testes aritméticos ou referências subjetivas de fome ou cansaço entre desjejuns com alto teor de calorias ou de proteinas. Entretanto, os desjejuns que proporcionaram menos do que 400 calorias influiram adversamente no desempenho.

Considerando que a população objeto deste estudo se enquadra dentro da faixa etária pesquisada acima, cabe mencionar que, segundo a distribuição das crianças do estudo, em relação ao consumo de calorias (Tabela 6), o percentual de escolares situados abaixo de 400 calorias foi igual a $82,1 \%$.

Quanto à ingestão protídica, o fato de que $62,6 \%$ das crianças do estudo não tenham conseguido uma cobertura de $20 \%$ das suas necessidades diárias (Tabela 4), reabre a questão da responsabilidade das demais refeições do dia no preenchimento das necessidades totais.

Quanto a conseqüências imediatas, cabe referência aos lowa Breakfast Studies 4 (1962) feitos em universitários e utilizando um desjejum considerado adequado em relação às calorias ( $1 / 4$ das necessidades diárias), mas proporcionando apenas $40 \%$ do total de proteinas contidas no chamado desjejum básico (em que as proteinas correspondem a $1 / 4$ dessas necessidades também). Esse baixo teor de proteínas determinou um nível sanguineo de glicose significantemente inferior ao nível de jejum, três horas após a refeição. Por outro lado, a ingestão de um teor de proteínas igual a 1/4 das necessidades diárias foi apropriado no sentido de manter a glicemia significantemente acima dos níveis de jejum, nas últimas horas da manhã. A importância desse fato é óbvia, se for aceita a idéia de que a fome e a eficiência estão relacionadas ao teor de açúcar no sangue.

A presença de frequiência apreciável de valores aberrantes nos percentís mais elevados (Tabela 4) explica o fato de que o valor da média $(17,29 \%)$ tenha sido bem mais elevado que os da classe à qual correspondeu a moda $(0 \mid-5 \%)$.

\section{2. Valores absolutos das calorias $e$ nutrientes}

Destaca-se, na Tabela 5, a grande variabilidade em torno da média, mais acentuada nos lipides e, em ordem decrescente, nos prótides, calorias e glícides.

Em relação à distribuição das crianças do estudo segundo o consumo de calorias e de proteínas, em gramas, (Tabelas 6 e 7), os comentários já tecidos em função da cobertura dispensam outra espécie de análise.

$\mathrm{Na}$ distribuição segundo o consumo de glicides, em gramas (Tabela 8), em $53,2 \%$ da amostra, o consumo foi inferior a $40 \mathrm{~g}$, o que significa ingestão insuficiente no desjejum habitual da criança em idade escolar.

No caso dos lípides, nota-se o valor baixo da média - 6,1 g - considerandose também que a moda, 184 (Tabela 9), está situada na classe em que o consumo 
ROSENBtrG, O. O desjejum dos alunos das quatro primeiras séries de nivel I das escolas da Rede Municipal de Ensino de São Paulo, SP - Brasil. Rer. Saúde públ., S. Paulo, 11: $465-79,1977$.

toi nulu ou inferior a 5 g. Tal contribuição, segundo os padrões recomendados en relação ao desjejum, pode ser considerada bastante escassa.

\section{3 Composiçäo centesimal}

A quota correspondente aos glicides foi proporcionalmente mais representativa do que a das proteinas e dos lipides.

A amplitude de variaçào em torno da média (Tabela 10) foi a mais acentuada possível, o que denota a ocorrência de eventos em que os glícides cobriram a totalidade das calorias. Tal fato significa, dentro de una refeição tım desequilibrio centesimal absoluto.

$\mathrm{Na}$ distribuição dos escolares segundo o percentual correspondente aos hidratos de carbono, (Tabela 11), verifica-se que na maioria dos casus $(56,8 \%)$, us glicides contribuiram com un percentual igual ou superior a $60 \%$ do total calórico do desjejum.

É oportuno lembrar aqui a intluência do poder aquisitivo na qualidade dos alimentos (Soboll 1i, 1973), uma vez que os hidratos de carbono são, na escala dos gêneros, os de preço mais baixo.

Para os prótides, o valur médio, inferior a 10\% (Tabela 10), adquire maior força quando se constata que o mesmo fato se repete em metade da população (Tabela 12).

Quanto aos lipides, o valor médio, inferior a $20 \%$ do total calórico (Tabela 10), é encontrado tambén, praticamente, em metade da população (Tabela 13).

Enı resumo, a composição centesimal do desjejum caracterizou-se por uma participação glicídica excessiva, em relação às fraçóes protídicas e, principalmente, lipidicas.

\subsection{Alunos que compareceram às aulas em completo jejum $(12,63 \%)$}

Cabem aqui, algumas considerações sobre as consequiências imediatas da omissão do desjejum. Tal questão foi objeto de capítulo especial dentro dos estudos de lowa sobre o desjejum *.

Limitando tais consideraçóes ao grupo em idade escolar e ao comportamento, verifjcou-se que a maioria das crianças apresentava melhor atitude e melhor desempenho durante o periodo no qual recebiam o desjejum do que no periodo em que ele foi omitido. Alguns alunos eran descuidados e desatentos durante as ultimas horas da manhã, quando não recebiam a primeira refeição. Passando a um regime alimentar em que a tomavam, apresentaram melhora nitida, especialmente no desempenho das suas tarefas.

O efeito da umissão fui também estudado en relação à qualidade de certas respostas fisiológicas nas últimas horas da manhã, ficando comprovado que algumas reaçós eram prejudicadas pela falta do desjejum.

Considerando que essas experiências foram realizadas em escolares submetidus a um regime alimentar diário adequado, cabe perguntar sobre as conseqüências da omissão do desjejum nos casos em que esse reginle é habitualmente deficitário, como para grande número de crianças que constituem a população deste estudo.

\subsection{Análise qualitativa do desjejum.}

Se, em $12,63 \%$ dos alunos, a ingrestão de alimentos de qualquer natureza na primeira refeição do dia foi totalmente nula, cabe aqui considerar os casos em que, em termos de composição do cardápio, o desjejum pôde ser considerado altamente insatisfatório.

\subsubsection{Desjejum constituido exclusivamente por café oul chá com açúcar $(5,78 \%)$}

Nestes, a contribuição almentar deve-se exclusivamente ao açúcar. A propósito, é oportuno citar os experimentos levados a 
ROSENBURG, O. O desjejum dos alunos das quatro primeiras séries de nível I das escolas da Rede Municipal de Ensino de São Paulo, SP -- Brasil. Rev. Saúde pribl., S. Paulo, 11: $465-79,1977$.

efeito nos estudos de Iowa + , com universitários, usando somente o café como desjejum.

A análise dos dados mostrou que um desjejum constituido apenas de café resultou em amplitude significantemente maior do tremor neuro-muscular durante as últimas horas matinais. Do mesmo modo, o café simples aumentou o tempo de "reação de escolha" usado como teste, em comparação ao tempo obtido com outro tipo de primeira refeição. E o rendimento do trabalho nas últimas horas da manhã foi maior depois de desjejuns mais habituais, do que após ı̇m café simples.

\subsection{Café oul chá com pão $(8,15 \%)$}

Ainda que se encontre aqui alguma contribuição em proteínas vegetais, é óbvia a predominância dos componentes energéticos. Somados estes casos aos mencionados no item anterior $(5,78 \%)$, resulta um total de $13,93 \%$ de casos em que o desjejum, ainda que presente, pode ser considerado absolutamente insatisfatório.

\subsubsection{Ausência de leite, margarina on manteiga na primeira refeição}

Considerando o alto valor do leite na alimentação do escolar (FAO ${ }^{\circ}$, 1954) e considerando também que nas classes mais abonadas o "café com leite e pão e muitas vezes a manteiga" vem se mantendo como a mais usual primeira refeição na cidade de São Paulo (Meira 1ª 1963), o fato de que o leite esteja ausente em $49,73 \%$, e a margarina ou manteiga, em $57,11 \%$ dos casos pode ser encarado como um desvio grave, pelo qual porém os pais ou responsáveis não podem ser incrimidados. Este desvio se repetirá igualmente em relação a outros alimentos reconhecidos como indispensáveis, inclusive pelas classes menos favorecidas, e nas demais refeições do dia, em decorrência de um poder aquisitivo pequeno (Soboll 1n; Azevedo, B. P. e col. ${ }^{2}$ ).

\subsubsection{Ausência de frutas}

A irrisória contribuição das frutas $1,57 \%$ dos desjejuns - pode ser explicada, em grande número de casos, pela imutabilidade de hábitos culturais defeituosos em relação ao consumo de vegetais, em geral, e à organização dos cardápios, em particular.

É fato reconhecido que certas frutas regionais, de ótima qualidade, encontram-se, na lista de gêneros, entre os de mais baixo preço. Mas o hábito arraigado de que elas devam ser usadas apenas como sobremesa e nas refeições maiores, prejudica o seu consumo. A superstição de que as frutas associadas ao leite, fazem mal ao organismo (herança dos tempos da escravidão), ainda subsiste.

Caberia agora lembrar a influência positiva que uma educação alimentar dirigida não só à criança como aos pais, traria, no sentido de ampliar o cardápio do desjejum, incluindo nele as frutas.

É oportuno ainda citar De Lamare 11, e colocar as frutas no contexto do desjejum tradicional: "Uma fruta pela manhã é um hábito indispensável,... e o pão com manteiga é uma boa tradição, acompanhando o café com leite".

Muito já foi dito sobre as danosas consequiências da pobreza qualitativa e quantitativa do desjejum. Mas a extensão do prejuizo, no caso particular da criança que vai à escola pela mahã, não parece ter sido suficientemente avaliada. É preciso ter em mente as muitas horas do jejum noturno, às quais se somarão, após uma primeira refeição sempre escassa, três e meia a quatro horas de permanência na escola, sob trabalho mental intensivo.

É preciso lembrar igualmente aqueles casos em que a refeição, além de pequena, é de má qualidade e, mais grave ainda, em que nenhum alimento é dado à criança antes de sua saída para a escola. 
ROSENBURG, O. O desjejum dos alunos das quatro primeiras séries de nível I das escolas da Rede Municipal de Ensino de São Paulo, SP - Brasil. kev. Saúde públ., S. Paulo, 11: $465-79,1977$.

Apj́s as investigações patrocinadas pelo Cereal Institute, de Chicago ${ }^{*}$, que incluiram escolares de 12 a 14 anos de idade, poucas dúvidas restaram sobre a importância de uma primeira refeição adequada, no rendimento intelectual do periodo da manhã. Tais estudos redundaram em várias conclusões, das quais, as pertinentes ao desjejum, podem ser resumidas da seguinte maneira:

"A omissão do desjejum, ou a má qualidade do mesmo, resultaram em eficiência diminuída nas últimas horas da manhã, e em desempenhos fisiológicos mais pobres. Foi demonstrada, também, em tais casos, uma atitude menos integrada no trabalho escolar, o que prejudica o seu rendimento".

\section{CON CLUS Õ S}

1. Um contigente de $12,63 \%$ dos alunos das quatro primeiras séries das Unidades Municipais de Ensino vai à escola, pela manhã, em completo jejum.

2. A média do consumo de calorias no desjejum foi igual a $10,57 \%$ das necessidades diárias de acordo com a idade e o sexo, e o consumo mais freqüente foi de 5 a menos do que $10 \%$ dessas necessidades.

3. A média do consumo de proteínas foi igual a $17,29 \%$ das necessidades diárias, e o consumo mais frequiente foi de zero a menos do que $5 \%$ dessas necessidades.

4. A média do consumo de lípides, ou gorduras, foi igual a 6,7 gramas, e o consumo mais frequiente foi de zero a menos do que 5 gramas.

5. A composição centesimal do desjejum caracterizou-se por uma participação excessiva do componente glicídico, em detrimento do protídico e, principalmente, do lipídico.

RSPU-B/379

RosenbuRG, O. [Breakfast of first through fourth grade school-children in $S$. Paulo, Brazill Rev. Saúde públ., S. Paulo, 11:465-79, 1977.

ABSTRACT: A study of 380 schoolchildren from the first through the fourth grades belonging to the $S$. Paulo Municipality regarding breakfast showed a deficiency in quality and quantity of this meal in a vast majority of this papulation. As much as $12,63 \%$ of these children go to school on an empty stomach. The average calory intake was $10,57 \%$ of daily requirements; most frequently it was between 5.0 and $10.0 \%$. The average protein intake was equal to $17,29 \%$ of daily requirements; most frequently it was between zero and $5,0 \%$. The average intake of fats was 6,7 grammes, most frequently it was between zero and 5,0 grammes. The percentual composition of breakfast among these children showed an expressive participation of the glicidic component in detriment of the proteic and mainly the lipidic one.

UnITERMS: Child nutrition. Nutrition surveys. S. Paulo, Brazil: Nutrition disorders. 
ROSENBURG, O. O desjejum dos alunos das quatro primeiras séries de nível I das escolas da Rede Municipal de Ensino de São Paulo, SP - Brasil, Rev. Saúde pübl., S. Paulo, 11: $465-79,1977$.

\section{REFERENCIAS BIBLIOGRAFICAS}

1. ARVEDSON, I, et al, Breakfast habits of Swedish school children. J. Amer. Dietet. Ass., $55: 257-61,1969$.

2. AZEVEDO, B. P. \& IANNINI, M. Nível salarial e alimentação no Estado de Minas Gerais, Brasil. Rev. bras. Malar., $22: 461-7,1970$.

3. BRIDGES, M. A. \& MATTICE, M. R. Food and beverage analysis. 2nd ed. Philadelphia, Lea \& Febiger, 1942.

4. A COMPLETE summary of the Iowa breakfast studies. Chicago, Cereal Inst., 1962.

5. FACULdAdE DE SAUdE PÚBLICA. UNIVERSIDADE DE SAO PAULO. Departamento de Nutrição. Dados compilados de aiferentes tabelas de composição química dos alimentos. São Paulo, 1971.

6. FAO. La alimentación escolar y su influencia en la nutrición del niño. Roma, 1954. (Estudios sobre nutrición. 10)

7. FONSECA, W. S. da Bases da alimentacão escolar. Rio de Janeiro, Serviço de Alimentação da Previdência Social (SAPS), 1953. (Coleção Ensaio e Debate Alimentar, v. 1).

8. FRANCO, G. Tabela de composição química $e$ do teor vitamínico dos alimentos. 3a. ed. Rio de Janeiro, Serviço de Alimentação da Previdència Social (SAPS), 1960.

9. GIULIANELLI, S. Desenvolvimento futuro dos programas de merenda escolar.
[Apresentada ao Seminário Regional de Merenda Escolar, Bogotá, 1961]

10. HARRIS, W. H. A survey of breakfast eaten by high school students, $J$. Sch. Hlith, 40:323-5, 1970.

11. LAMARE, R. de Manual básico de alimentacão escolar. Rio de Janeiro, Victor Publ., 1968.

12. LESER, W. \& BARBOSA, V. Relacionamento de certas caracteristicas popuiacionais com a mortalidade infantil no município de São Paulo de 1950 a 1970. Probl. bras., 10(109):17-33, 1972.

13. LEUNG, W. T. Wu \& FLORES, M. Tabela de composición de alimentos, para uso en America Latina. Guatemala, INCAP. ICNND, 1961.

14. MEIRA, R. A. A primeira refeição de um grupo de universitários de São Paulo. Sociologia, 25:425-9, 1963.

15. PIERSON, D. Hábitos alimentares em São Paulo: estudo comparativo, Rev. Arq. Mun. S. Paulo, 81:199-238, 1942.

16. SOBOLL, M. L. M. S. Nivel alimentar da população trabalhadora da cidade de São Paulo. Est. Sócio-Econom, S. Paulo, 1:1-32, jul. 1973.

17. WATT, B. K. \& MERRIL, A. L. Composition of foods. Washington, D. C. US Department of Agriculture, 196\%. (Agriculture Handbook. 8).

Recebudo para publicação em 19/05/197\%. Aprovado para publicacão em 14/0\%:197\%. 